(C) 2004 IEEE. Reprinted, with permission, from Steve Ling, On interpretation of graffiti digits and characters for eBooks: neural-fuzzy network and genetic algorithm approach . Industrial Electronics, IEEE Transactions on (Volume:51 , Issue: 2 ), April 2004. This material is posted here with permission of the IEEE. Such permission of the IEEE does not in any way imply IEEE endorsement of any of the University of Technology, Sydney's products or services. Internal or personal use of this material is permitted. However, permission to reprint/republish this material for advertising or promotional purposes or for creating new collective works for resale or redistribution must be obtained from the IEEE by writing to pubs-permissions@ieee.org. By choosing to view this document, you agree to all provisions of the copyright laws protecting it 


\title{
On Interpretation of Graffiti Digits and Characters for eBooks: Neural-Fuzzy Network and Genetic Algorithm Approach
}

\author{
K.F. Leung, F.H.F. Leung MIEEE, H.K. Lam MIEEE and S.H. Ling \\ Centre for Multimedia Signal Processing, Department of Electronic and Information \\ Engineering, The Hong Kong Polytechnic University, Hung Hom, Kowloon, Hong Kong
}

Abstract - This paper presents the rule optimization, tuning of the membership functions and optimization of the number of fuzzy rules, of a neural fuzzy network using genetic algorithm (GA). The objectives are achieved by training a proposed neural fuzzy network with rule switches. The proposed neural fuzzy network and GA are employed to interpret graffiti number inputs and commands for Electronic Books (eBooks).

Keywords: Genetic Algorithm, Neural Fuzzy Networks, Electronic Books

\section{INTRODUCTION}

GA is a powerful random search technique to handle optimization problems [1-3]. This is especially useful for complex problems with a large number of parameters that make the global analytical solutions difficult to obtain. It has been widely applied in different areas such as fuzzy control [4-6, 10], path planning [7], greenhouse climate control [8], modeling and classification $[9,13]$ etc..

Neural fuzzy networks (NFNs) have been proved to be a universal approximator [11], which can approximate nonlinear functions to an arbitrary accuracy. Expert knowledge and experience can be incorporated into an NFN [11,13]. In view of its specific structure, 
an NFN can be used to realize a learning process [2]. In general, learning involves two aspects: (1) defining a network structure based on fuzzy rules, and (2) choosing an algorithm to realize the learning process. Usually, the network structure is fixed for a learning process as the number of rules is fixed. However, this fixed structure may not provide the best performance within a given training period. If the structure of the NFN is too complicated, the training period will be long and the implementation cost will be high.

Notebook Computers and Personal Digital Assistants (PDAs) are widely accepted by the public. In particular, Electronic Books (eBooks) are winning their popularity as a kind of media that can offer rich contents and features such as multimedia presentations, instant dictionaries and bookmark functions etc. within a small handheld device. As shown in Fig. 1, an eBook Reader should have no keyboard or mouse. The main input device is a touch screen. Typing can be done by using an on-screen keyboard. Yet, this is not a convenient way of input. One natural way of inputting information to the eBook is to write directly on the touch screen. However, computers are only good at numerical manipulation, while the interpretation of graffiti is a symbolic manipulation process. Thus, a way to convert a symbolic manipulation process to a numerical manipulation process should be found. Different methodologies for recognizing handwritten characters can be found in the literature. In general, four different approaches [14] are used: template matching, statistical techniques, structural techniques, and neural/neural-fuzzy networks. The idea of the template matching approach is to determine the best match between the stored templates and the input. For statistical techniques, statistical decision theory is employed to determine the class to which the input belongs. Hidden Markov 
modeling [15] is one of the popular statistical techniques for handwritten character recognition. On applying structural techniques, some complex patterns are represented by some simpler patterns. Based on these simpler patterns, the input can be classified. Examples of structural techniques include grammatical [16] and graphical [17] methods. In general, the main idea of the neural/neural-fuzzy network approaches [18] is to learn the features of the training patterns through some processes. The input's features can then be recognized using the trained neural/neural-fuzzy network. The objective of this paper is to develop an algorithm recognizing handwritten digits and characters. An NFN with rule switches is proposed to perform the interpretation of graffiti. A GA with arithmetic crossover and non-uniform mutation [3] will be employed to train the proposed NFN. The result is an interpreter that can interpret the digits 0 to 9 and three (control) characters, namely Backspace, Carriage Return, and Space. Though this NFN, the optimal fuzzy rules and membership functions can be tuned. It is applied to an eBook reader experimentally.

This paper is organized as follows. The proposed NFN with rule switches will be presented in section II. A graffiti interpreter, which is formed by the proposed NFN, is proposed in section III. The tuning of the membership functions and rules of the NFN will be presented. Application results on interpreting graffiti digits and characters for eBooks will be given in section IV. A conclusion will be drawn in Section V.

\section{NEURAL FuZZY NETWORK WITH Rule SwitchES}

We use a fuzzy associative memory (FAM) [12] type of rule base for the NFN. An FAM is formed by partitioning the universe of discourse of each fuzzy variable according 
to the level of fuzzy resolution chosen for the antecedents, thereby generating a grid of FAM elements. The entry at each grid element in the FAM corresponds to a fuzzy premise. An FAM is thus interpreted as a geometric or tabular representation of a fuzzy logic rule base. For an NFN, the number of possible rules may be too large. This makes the network complex while some rules may not be necessary. The implementation cost is also unnecessarily high. Thus, a multi-input-multi-output NFN, which can have an optimal number of rules and membership functions, is proposed. The main difference between the proposed network and the traditional network is that a unit step function is introduced to each rule. The unit step function is defined as,

$\delta(\varsigma)=\left\{\begin{array}{l}0 \text { if } \varsigma \leq 0 \\ 1 \text { if } \varsigma>0\end{array}, \varsigma \in \mathfrak{R}\right.$

This is equivalent to adding a switch to each rule in the NFN. The rule is used if the corresponding rule switch is closed. Otherwise, the rule is not necessary. Referring to Fig. 2, we define the input and output variables as $x_{i}$ and $y_{j}$ respectively; where $i=1$, $2, \ldots, n_{i n} ; n_{\text {in }}$ is the number of input variables; $j=1,2, \ldots, n_{\text {out }} ; n_{\text {out }}$ is the number of output variables. The behaviour of $y_{j}$ of the NFN is governed by $m_{f}$ fuzzy rules in the following format;

$$
\begin{aligned}
R_{g}: \quad \mathrm{IF} & x_{1}(t) \text { is } A_{1 g}\left(x_{1}(t)\right) \text { AND } x_{2}(t) \text { is } A_{2 g}\left(x_{2}(t)\right) \text { AND } \ldots \text { AND } x_{n_{i n}}(t) \text { is } \\
& A_{n_{i n} g}\left(x_{n_{i n}}(t)\right) \text { THEN } y_{j}(t) \text { is } w_{j_{g}}, g=1,2, \ldots, m_{f} ; t=1,2, \ldots, n_{d}
\end{aligned}
$$

where $m_{f}$ also denotes the number of membership functions; $n_{d}$ denotes the number of input-output data pairs; $w_{j_{g}}, j=1,2, \ldots, n_{\text {out }}$, is the output singleton of the rule $g$. In this NFN, the membership function is a bell-shaped function given by, 
$A_{i_{g}}\left(x_{i}(t)\right)=e^{\frac{-\left(x_{i}(t)-\bar{x}_{i g}\right)^{2}}{2 \sigma_{i_{g}}^{2}}}, i=1,2, \ldots, n_{i n} ; g=1,2, \ldots, m_{f}$

where $\bar{x}_{i_{g}}$ and $\sigma_{i_{g}}$ are the mean value and the standard deviation of the membership function respectively. The grade of membership of each rule is defined as,

$\mu_{g}(t)=A_{1_{g}}\left(x_{1}(t)\right) \times A_{2_{g}}\left(x_{2}(t)\right) \times \ldots \times A_{n_{\text {ing }}}\left(x_{n_{\text {in }}}(t)\right), g=1,2, \ldots, m_{f}$

The $j$-th output of the NFN, $y_{j}(t)$, is defined as,

$y_{j}(t)=\frac{\sum_{g=1}^{m_{f}} \mu_{g}(t) w_{j_{g}} \delta\left(\varsigma_{j_{g}}\right)}{\sum_{g=1}^{m_{f}} \mu_{g}(t)}, j=1,2, \ldots, n_{\text {out }}$

where $\varsigma_{j_{g}}$ denotes the rule switch parameter of the $g$-th rule.

\section{Tuning OF MEMBERShip FunCtions AND Rules OF THE NEURAL FuZZY Network}

In this section, the proposed NFN is employed to interpret graffiti digits and characters for eBooks. Fig. 3 shows the block diagram of the interpreter with $m$ graffiti inputs. It consists of $m$ NFNs and a graffiti determiner. The input-output relationships of the NFNs are trained using GA with arithmetic crossover and non-uniform mutation [3]. The inputoutput relationship of one of the $m$ neural networks in Fig. 3 is described by,

$\mathbf{y}^{d}(t)=\mathbf{z}(t) \equiv \frac{\mathbf{x}(t)}{\|\mathbf{x}(t)\|}, t=1,2, \ldots, n_{d}$

where $\mathbf{y}^{d}(t)=\left[\begin{array}{llll}y_{1}^{d}(t) & y_{2}^{d}(t) & \cdots & y_{n_{i \nu}}^{d}(t)\end{array}\right]$ and $\mathbf{z}(t)=\left[\begin{array}{llll}z_{1}(t) & z_{2}(t) & \cdots & z_{n_{i n}}(t)\end{array}\right]$ are the desired outputs and the inputs of the NFN respectively. 
$\mathbf{x}(t)=\left[\begin{array}{llll}x_{1}(t) & x_{2}(t) & \cdots & x_{n_{i n}}(t)\end{array}\right]$ is the vector of uniformly sampled points of the graffiti.

$\|\cdot\|$ denotes the $l_{2}$ norm. The fitness function is defined as,

fitness $=\frac{1}{1+e r r}$

and $e r r$ which is the mean square error (MSE) is defined as,

$e r r=\sum_{k=1}^{n_{\text {in }}} \frac{\sum_{t=1}^{n_{d}}\left(\frac{y_{k}(t)}{\|\mathbf{y}(t)\|}-\frac{y_{k}^{d}(t)}{\left\|\mathbf{y}^{d}(t)\right\|}\right)^{2}}{n_{\text {in }} n_{d}}$

The objective is to maximize the fitness value of (7) by setting the chromosome to be $\left[\begin{array}{llll}\bar{x}_{i g} & \sigma_{i g} & \varsigma_{g} & w_{j_{g}}\end{array}\right]$ for all $i, j$ and $g$. It can be seen from (6), (7) and (8) that a larger fitness value implies a smaller error value. From (7) and (8), the NFN is trained such that the outputs are similar to its inputs. As shown in Fig. 3, we have $m$ sets of graffiti training samples for $m$ NFNs correspondingly. Each set of graffiti training samples is used to train its corresponding NFN. During the operation, the sampled points of the input graffiti will be fed to all the $m$ neural fuzzy networks. The output of the $m$ neural fuzzy networks will be fed to the graffiti determiner to generate the final result that indicates the possible graffiti input. The graffiti determiner measures the similarity between the input graffiti and the outputs of the NFNs. The similarity of an input graffiti to the output of an NFN is defined as,

$S_{i}=\left\|\overline{\mathbf{y}}_{i}-\overline{\mathbf{z}}\right\|, i=1,2, \ldots, m$

where,

$\overline{\mathbf{y}}_{i}=\frac{\mathbf{y}_{i}}{\left\|\mathbf{y}_{i}\right\|}=\left[\begin{array}{llll}\bar{y}_{1}(t) & \bar{y}_{2}(t) \quad \cdots \quad \bar{y}_{n_{i n}}(t)\end{array}\right], i=1,2, \ldots, m$ 
$\overline{\mathbf{z}}=\frac{\mathbf{Z}}{\|\mathbf{z}\|}=\left[\begin{array}{llll}\bar{z}_{1}(t) & \bar{z}_{2}(t) & \cdots & \bar{z}_{n_{i n}}(t)\end{array}\right]$

$\overline{\mathbf{y}}_{i}$ and $\overline{\mathbf{z}}$ denote the normalized outputs and the normalized input of the NFNs respectively. A smaller value of $S_{i}$ implies a closer match of the input graffiti to the graffiti represented by the $i$-th NFN. The smallest similarity value among the $m$ NFNs is defined as,

$S_{j}=\min _{i} S_{i}$

The index $j$ of (12) is the output of the graffiti determiner, which indicates the $j$-th graffiti is the most likely input graffiti.

\section{Application ExAmPle And Results}

The interpretation of graffiti digits and characters for eBooks by the proposed NFN will be presented in this section. A point on the eBook screen is characterized by a number based on the $x-y$ coordinates on a writing area. The size of the writing area is $x_{\max }$ by $y_{\max }$. The bottom left corner is set as $(0,0)$. Ten uniformly sampled points of the graffiti will be taken as the inputs of the interpreter. The points are taken in the following way. First, the input graffiti is divided into 9 uniformly distanced segments characterized by 10 points, including the start and the end points. Each point is labeled as $\left(x_{i}, y_{i}\right), i=1,2, \ldots$, 10. The first 5 points, $\left(x_{i}, y_{i}\right), i=1,3,5,7$ and 9 , taken alternatively are converted to 5 numbers $\rho_{i}$ respectively by using the formula $\rho_{i}=x_{i} x_{\max }+y_{i}$. The other 5 points, $\left(x_{i}, y_{i}\right), i$ $=2,4,6,8$ and 10 , are converted to 5 numbers respectively by using the formula $\rho_{i}=$ $y_{i} y_{\max }+x_{i}$. These ten numbers, $z_{i}, i=1,2, \ldots, 10$, will be used as the inputs of the proposed NFN (with 10 inputs, 10 outputs, and 15 membership functions) with rule 
switches for each graffiti pattern. In our eBook application, the digits 0 to 9 and three (control) characters (backspace, carriage return and space) are interpreted. These graffiti are shown in Fig. 4 and the eBook graffiti interpreter thus has 16 NFNs. To train these NFNs, 100 sets of sampled points for each graffiti pattern are used. The input-output relationship of the NFNs is governed by (5). The fitness function of each NFN is given by (7), with

$e r r=\sum_{k=1}^{10} \frac{\sum_{t=1}^{100}\left(\frac{y_{k}(t)}{\|\mathbf{y}(t)\|}-\frac{y_{k}^{d}(t)}{\left\|\mathbf{y}^{d}(t)\right\|}\right)^{2}}{1000}$

GA with arithmetic crossover and non-uniform mutation [3] is employed to tune the membership functions and numbers of rules of the NFN of (5). The objective is to maximize the fitness function of (7). The best fitness value is 1 and the worst one is 0 . The population size is 10 . The lower and upper bounds of the link weights are defined as $0 \geq \bar{x}_{i g}, \sigma_{i g}, \varsigma_{g}, w_{j_{g}} \geq 1, i=1,2, \ldots, 10 ; j=1,2, \ldots, 10 ; g=1,2, \ldots, 15$. The chromosomes of the GA process used are $\left[\begin{array}{llll}\bar{x}_{i g} & \sigma_{i g} & \varsigma_{g} & w_{j_{g}}\end{array}\right] \quad i=1,2, \ldots, 10 ; j=1$, $2, \ldots, 10 ; g=1,2, \ldots, 15$. The initial values of the link weights are randomly generated. The number of iterations to train the neural networks is 2000 , and the training is done for 30 times. After training, 30 graffiti samples of each kind of graffiti are used to test the performance of the trained NFNs. The results are tabulated in Table I. From this Table, it can be observed that the numbers of connected links in the NFNs are reduced after learning (each NFN has 150 rules initially). Fig. 5 shows the similarity values of each NFN for the 480 (30 for each type of graffiti) testing graffiti. It can be seen that the NFN trained by a particular graffiti will provide a smaller similarity values for that kind of 
graffiti. For example, in Fig. 5(a), the similarity values of the first 30 testing graffiti (digit ' 0 ') are smaller, as that NFN is trained by 100 digit ' 0 ' graffiti pattern. We have successfully implemented the graffiti digit and character interpreter in the eBook shown in Fig. 1. The image of inputting a digit ' 9 ' to the eBook reader using the proposed graffiti interpreter was captured and is shown in Fig. 6. Referring to this figure, the graffiti interpreter of the eBook reader recognizes that the input digit is ' 9 ' and takes the corresponding action of the Annotation feature. For comparison, a traditional neural fuzzy network and two three-layer feed-forward neural networks [11] are also employed as the networks in the graffiti interpreter of Fig. 3. The number of membership functions used for the traditional neural fuzzy network is 15 . The numbers of hidden nodes for the two neural networks are 15 and 21 respectively. GA with arithmetic crossover and nonuniform mutation [3] using the same control parameters of the proposed approach is employed for training. The best results over 30 simulations of training are tabulated in Table II to Table IV. For the neural network with hidden nodes of 21, the number of parameters to be tuned is nearly the same as that of the proposed NFN. It can be seen from Table I to Table III that the proposed approach provides a better performance than that of the traditional approaches (using a traditional neural fuzzy network with 15 membership functions and a traditional neural network with 15 hidden nodes) in terms of fitness value and/or number of rules. It can also be seen from Table I and Table IV that the proposed approach provides a similar performance to that of the traditional neural network with 21 hidden nodes in terms of fitness value. Still, the proposed NFN, after training, will have fewer network parameters than the traditional neural network with 21 hidden nodes, resulting in a lower cost of implementation. 


\section{CONCLUSION}

By introducing a switch to each rule, an NFN can be tuned to obtain the optimal number of rules, and learn the input-output relationship of an application using GA. This implies a lower cost of implementation. The proposed NFN with rule switches trained by GA has been applied to interpret graffiti digits and characters for eBooks.

\section{ACKNOWLEDGEMENT}

The work described in this paper was substantially supported by a Research Grant of the Centre for Multimedia Signal Processing, The Hong Kong Polytechnic University (project number A432).

\section{REFERENCES}

[1] J.H. Holland, Adaptation in natural and artificial systems. Ann Arbor, MI: University of Michigan Press, 1975.

[2] D.T. Pham and D. Karaboga, Intelligent optimization techniques, genetic algorithms, tabu search, simulated annealing and neural networks. Springer, 2000.

[3] Z. Michalewicz, Genetic Algorithm + Data Structures = Evolution Programs, 2nd ed. Springer-Verlag, 1994.

[4] B.D. Liu, C.Y. Chen, and J.Y. Tsao, "Design of adaptive fuzzy logic controller based on linguistic-hedge concepts and genetic algorithms," IEEE Trans. Systems, Man and Cybernetics, Part B, vol. 31 no. 1, pp. 32-53, Feb. 2001.

[5] Y.S Zhou and L.Y, Lai "Optimal design for fuzzy controllers by genetic 
algorithms," IEEE Trans. Industry Applications, vol. 36, no. 1, pp. 93-97, Jan.-Feb. 2000.

[6] C.F. Juang, J.Y. Lin, and C.T. Lin, "Genetic reinforcement learning through symbiotic evolution for fuzzy controller design," IEEE Trans. Systems, Man and Cybernetics, Part B, vol. 30, no. 2, pp. 290-302, April 2000.

[7] H. Juidette and H. Youlal, "Fuzzy dynamic path planning using genetic algorithms," Electronics Letters, vol. 36, no. 4, pp. 374-376, Feb. 2000.

[8] R. Caponetto, L. Fortuna, G. Nunnari, L. Occhipinti, and M. G. Xibilia, "Soft computing for greenhouse climate control," IEEE Trans. Fuzzy Systems, vol. 8, no. 6, pp. 753-760, Dec. 2000.

[9] M. Setnes and H. Roubos, "GA-fuzzy modeling and classification: complexity and performance," IEEE. Trans. Fuzzy Systems, vol. 8, no. 5, pp. 509-522, Oct. 2000.

[10] K. Belarbi and F. Titel, "Genetic algorithm for the design of a class of fuzzy controllers: an alternative approach," IEEE Trans. Fuzzy Systems, vol. 8, no. 4, pp. 398-405, Aug. 2000.

[11] M. Brown and C. Harris, Neuralfuzzy Adaptive Modeling and Control. Prentice Hall, 1994.

[12] B. Kosko, Neural Networks and Fuzzy System: A Dynamical Systems Approach to Machine Intelligence. Prentice Hall, 1991.

[13] F.H.F. Leung, H.K. Lam, S.H. Ling and P.K.S. Tam, "Tuning of the structure and parameters of neural network using an improved genetic algorithm," IEEE Trans. Neural Networks (to be published). 
[14] N. Arica and F.T. Yarman-Vural, "An overview of character recognition focused on off-line handwriting," IEEE Trans. Systems, Man, and Cybernetics - Part C: Application and Reviews, vol. 31, no. 2, May, 2001.

[15] M.A. Mohamed and P. Gader, "Generalized hidden Markov models - Part II: Application to handwritten word recognition," IEEE Trans. Fuzzy Syst., vol.8, pp. 82-95, Feb. 2000.

[16] M. Shridhar and F. Kimura, "High accuracy syntactic recognition algorithm for handwritten numerals," IEEE Trans. Syst., Man, Cybern., vol. SMC-15, pp. 152158, Jan. 1985.

[17] H.Y. Kim and J.H. Kim, "Handwritten Korean character recognition based on hierarchical random graph modeling," in Proc. Int. Workshop Frontiers Handwriting Recognit., 1998, pp. 577-586.

[18] R. Buse, Z.Q. Liu, and J. Bezdek, "Word recognition using fuzzy logic," IEEE Trans. Fuzzy Systems, vol. 10, no. 1, Feb. 2002. 


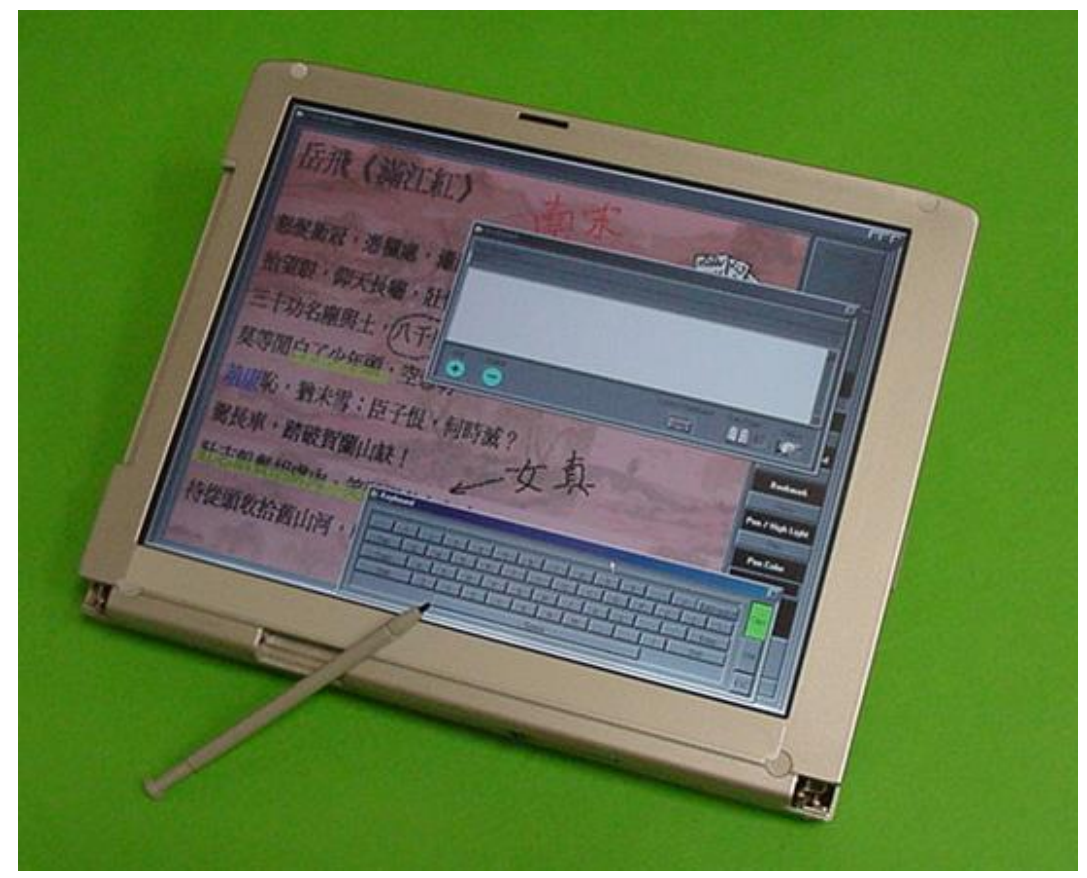

Fig. 1. eBook Reader. 


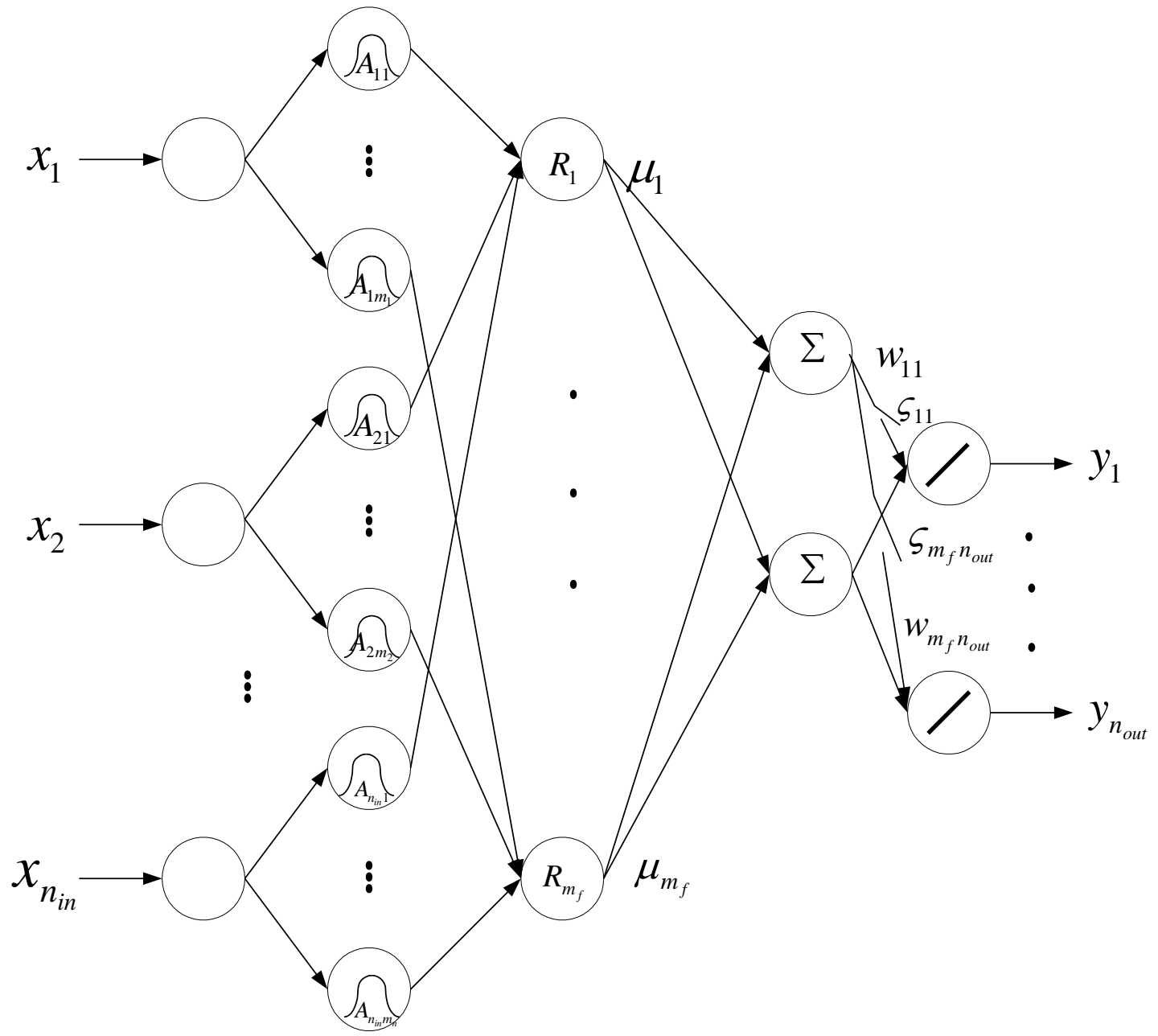

Fig. 2. Proposed neural fuzzy network. 


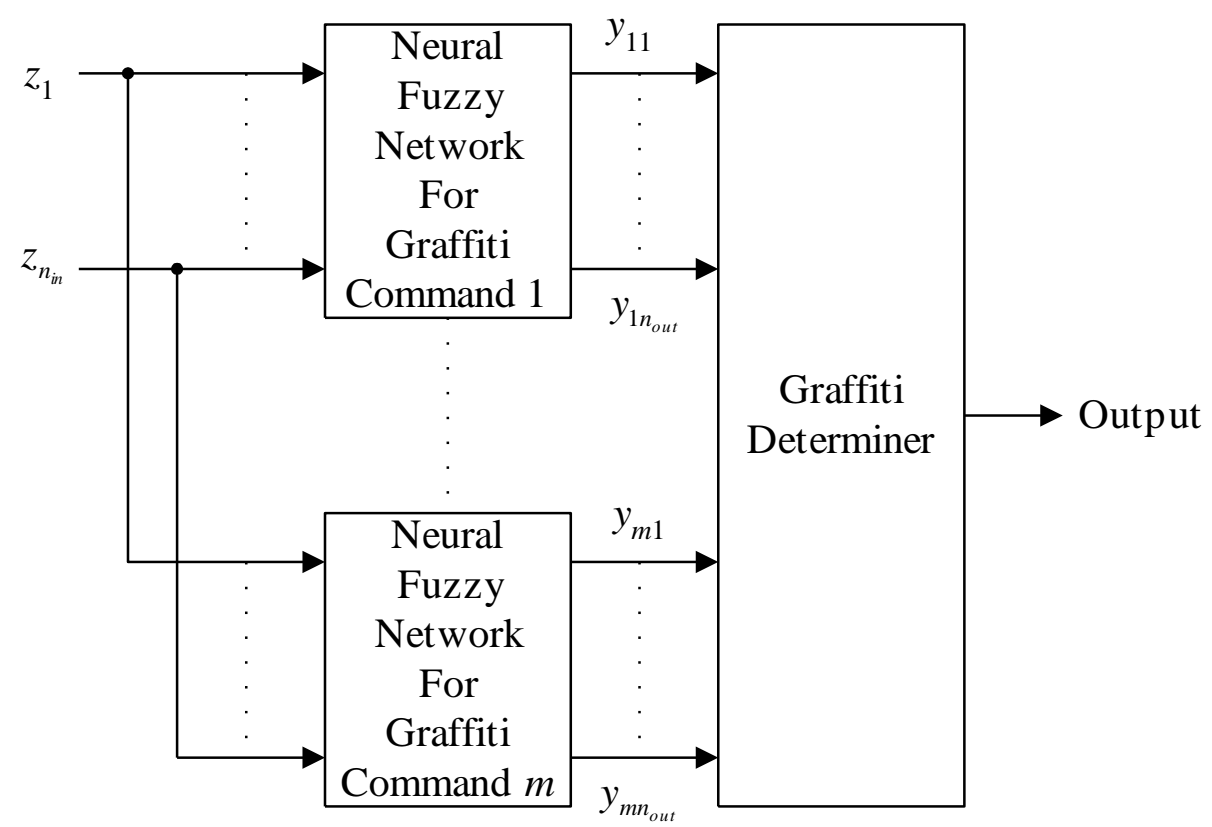

Fig. 3. Block diagram of the graffiti digit and character interpreter. 


\begin{tabular}{|c|c|c|c|}
\hline Digits or Characters & Strokes & Digits or Characters & Strokes \\
\hline $0(\mathrm{a})$ & 6 & \\
\hline $0(\mathrm{~b})$ & 7 & $8(\mathrm{a})$ & \\
\hline 1 & $8(\mathrm{~b})$ & \\
\hline 2 & & 9 & \\
\hline 3 & & Backspace & \\
\hline 4 & & Carriage Return & \\
\hline $5(\mathrm{a})$ & 5 & Space & \\
\hline $5(\mathrm{~b})$ & 5 \\
\hline
\end{tabular}

Fig. 4. Graffiti digits and characters (with the dot indicating the starting point of the graffiti). 


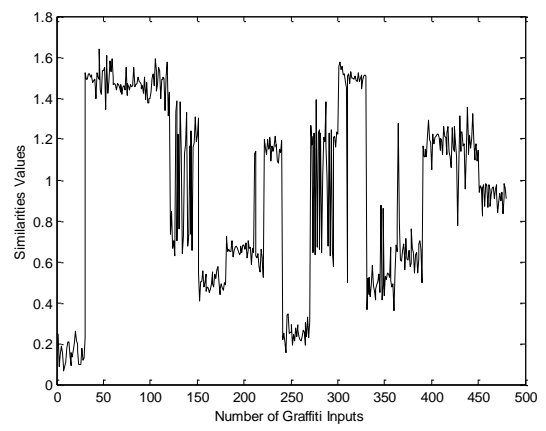

(a). Digit '0'(a).

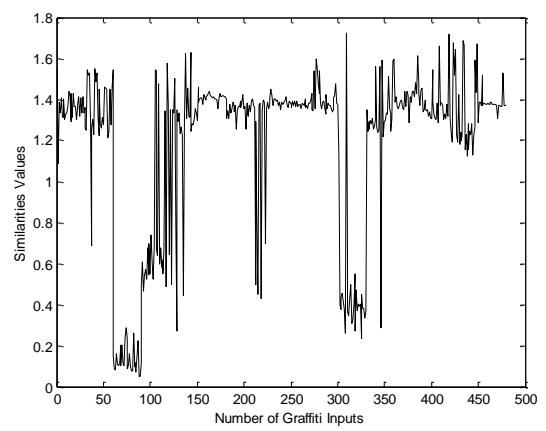

(c). Digit ' 1 '.

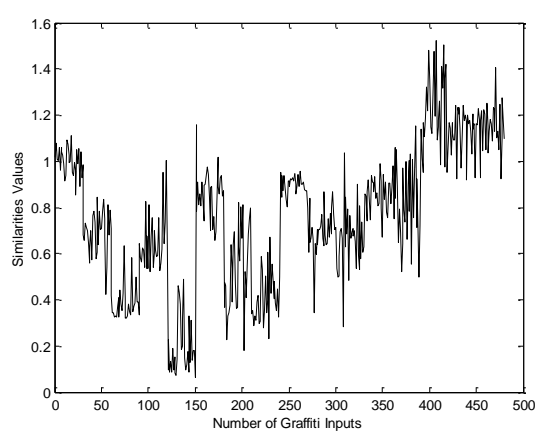

(e). Digit ' 3 '.

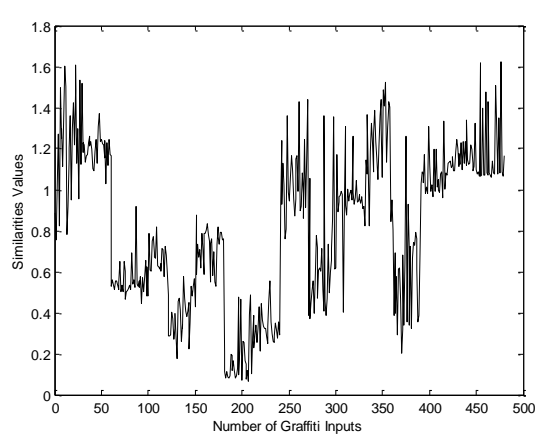

(g). Digit ' 5 '(a).

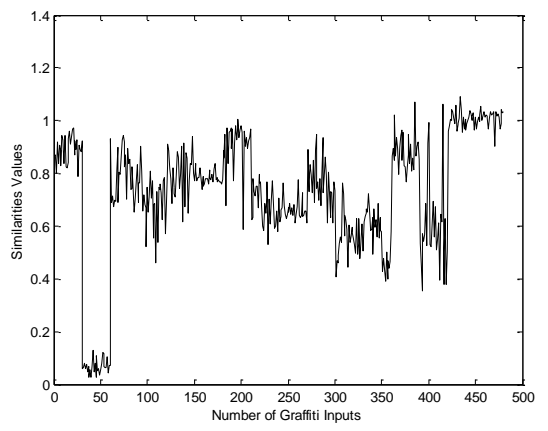

(b). Digit ' 0 '(b).

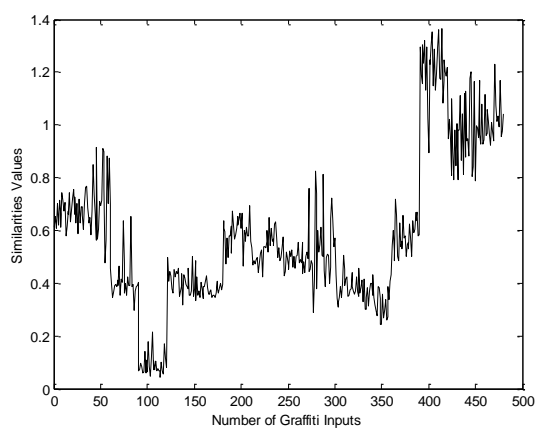

(d). Digit '2'.

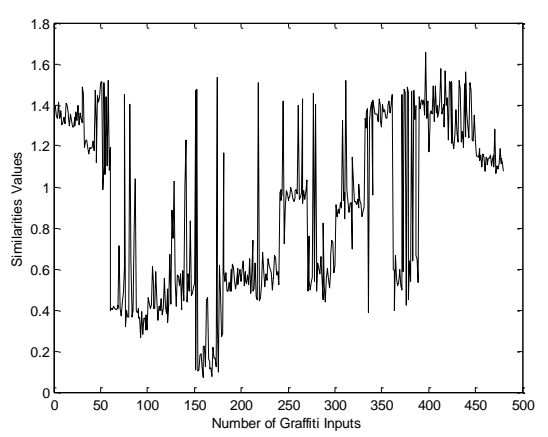

(f). Digit '4'.

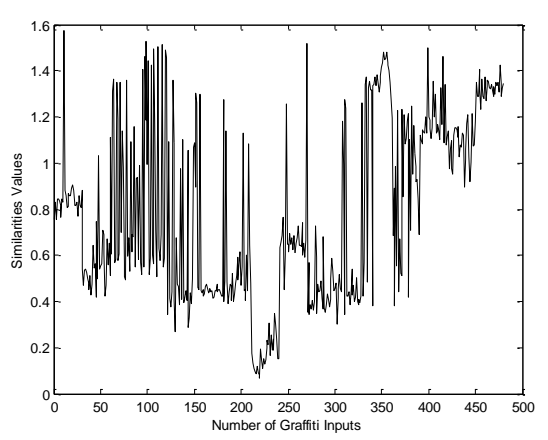

(h). Digit ' 5 '(b). 


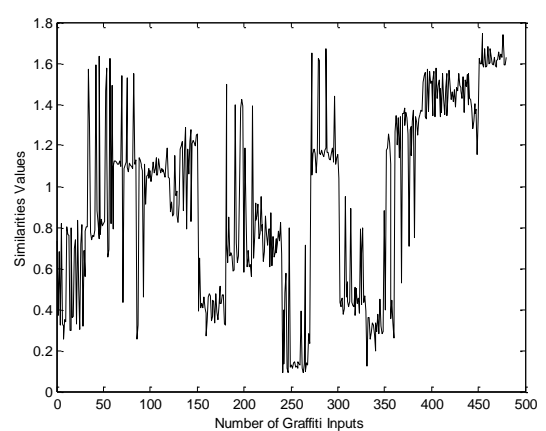

(i). Digit ' 6 '.

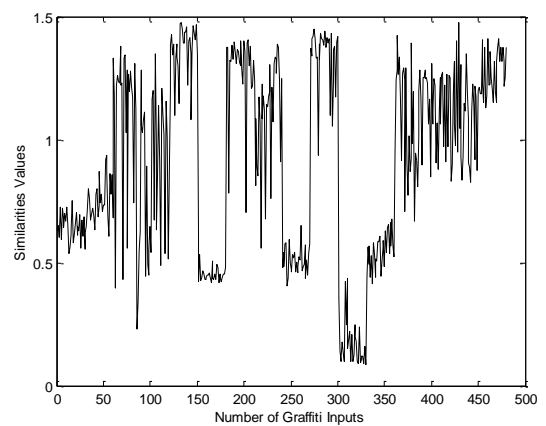

(k). Digit ' 8 '(a).

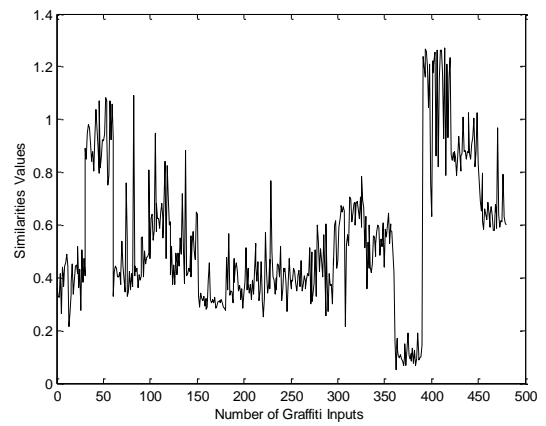

(m). Digit ' 9 '.

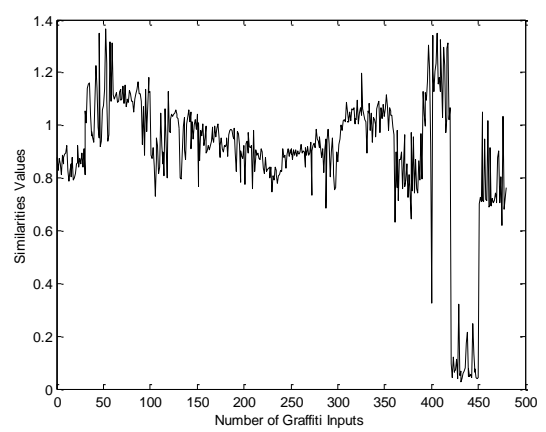

(o). Character 'carriage return'.

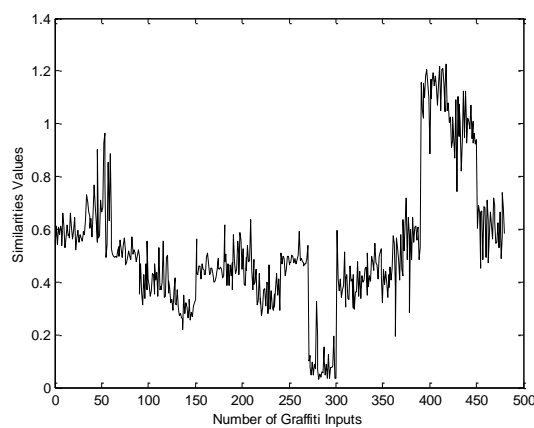

(j). Digit ' 7 '.

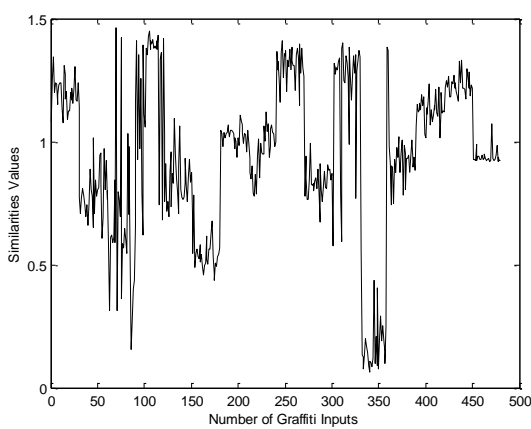

(l). Digit ' 8 '(b).

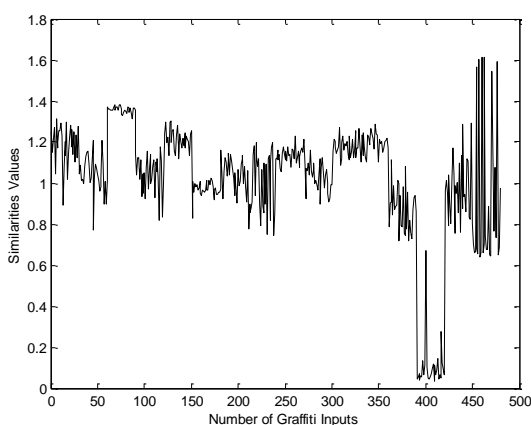

(n). Character 'backspace'.

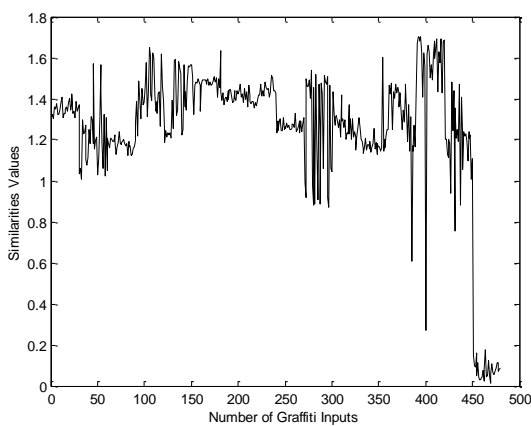

(p). Character 'space'.

Fig. 5. Similarity values of the 16 proposed neural fuzzy networks for the 480 ( 30 for each type) testing graffiti. 


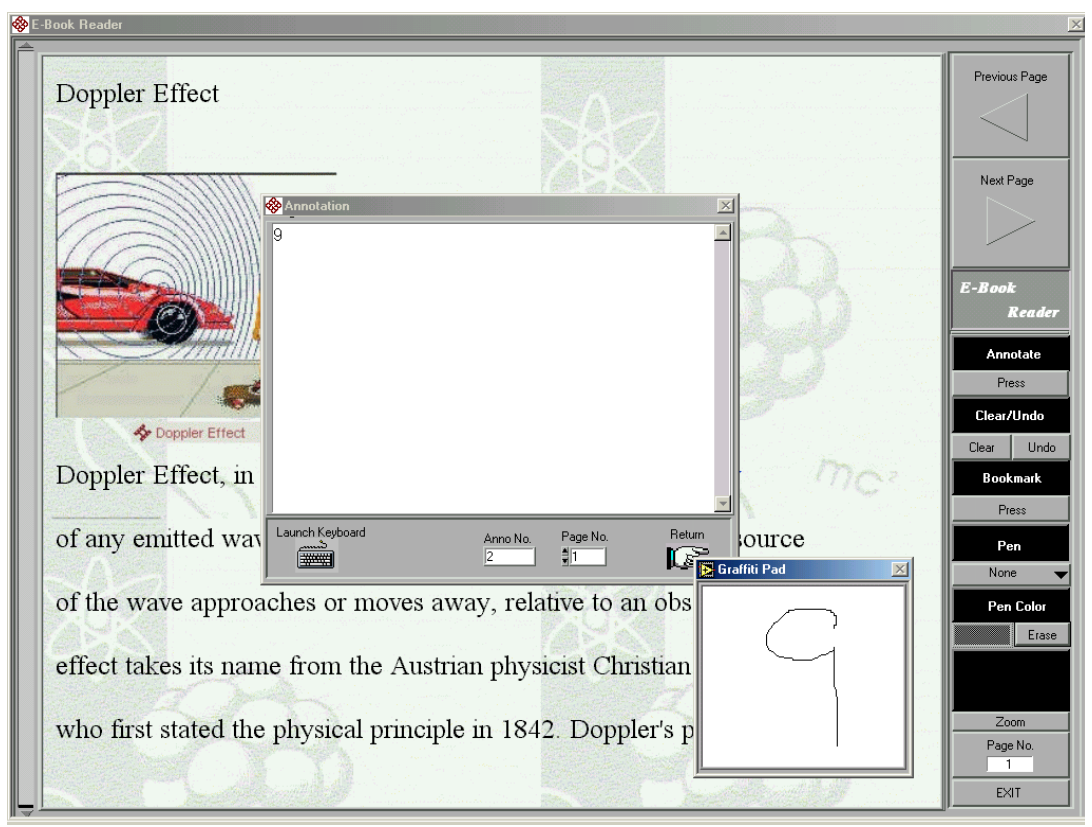

Fig. 6. Input of digit '9' to the Annotation window using the Graffiti Pad of the eBook. 


\begin{tabular}{|c|c|c|c|c|c|c|c|}
\hline $\begin{array}{c}\text { Neural } \\
\text { fuzzy } \\
\text { network }\end{array}$ & $\begin{array}{c}\text { Best } \\
\text { fitness } \\
\text { value }\end{array}$ & $\begin{array}{c}\text { Number } \\
\text { of rules } \\
\text { for the } \\
\text { Best } \\
\text { network }\end{array}$ & $\begin{array}{l}\text { Training } \\
\text { error } \\
\text { (MSE) for } \\
\text { the best } \\
\text { network }\end{array}$ & $\begin{array}{l}\text { Recognition } \\
\text { error rate (\%) } \\
\text { of the best } \\
\text { network for the } \\
\text { training pattern }\end{array}$ & $\begin{array}{l}\text { Testing } \\
\text { error } \\
\text { (MSE) for } \\
\text { the best } \\
\text { network }\end{array}$ & $\begin{array}{l}\text { Recognition } \\
\text { error rate }(\%) \\
\text { of the best } \\
\text { network for the } \\
\text { training pattern }\end{array}$ & $\begin{array}{c}\text { Average } \\
\text { fitness } \\
\text { value }\end{array}$ \\
\hline 0 (a) & 0.9986 & 80 & 0.0027 & 0 & $6.6667 \%$ & 0.9972 & 0.9968 \\
\hline $0(\mathrm{~b})$ & 0.9997 & 113 & 0.0003 & 0 & $0 \%$ & 0.9995 & 0.9995 \\
\hline 1 & 0.9978 & 89 & 0.0022 & 1 & $0 \%$ & 0.9978 & 0.9963 \\
\hline 2 & 0.9994 & 113 & 0.0006 & 0 & $0 \%$ & 0.9990 & 0.9991 \\
\hline 3 & 0.9995 & 109 & 0.0005 & 0 & $3.3333 \%$ & 0.9969 & 0.9992 \\
\hline 4 & 0.9988 & 92 & 0.0012 & 0 & $3.3333 \%$ & 0.9956 & 0.9979 \\
\hline $5(\mathrm{a})$ & 0.9992 & 100 & 0.0008 & 0 & $3.3333 \%$ & 0.9974 & 0.9986 \\
\hline 5 (b) & 0.9985 & 103 & 0.0015 & 0 & $0 \%$ & 0.9966 & 0.9975 \\
\hline 6 & 0.9992 & 93 & 0.0008 & 0 & $6.6667 \%$ & 0.9948 & 0.9979 \\
\hline 7 & 0.9991 & 113 & 0.0009 & 1 & $3.3333 \%$ & 0.9989 & 0.9988 \\
\hline $8(\mathrm{a})$ & 0.9995 & 108 & 0.0005 & 0 & $0 \%$ & 0.9962 & 0.9992 \\
\hline $8(\mathrm{~b})$ & 0.9997 & 98 & 0.0003 & 1 & $6.6667 \%$ & 0.9834 & 0.9994 \\
\hline 9 & 0.9990 & 107 & 0.0010 & 0 & $0 \%$ & 0.9987 & 0.9984 \\
\hline Back Space & 0.9996 & 97 & 0.0004 & 0 & $0 \%$ & 0.9976 & 0.9991 \\
\hline Return & 0.9996 & 113 & 0.0004 & 0 & $0 \%$ & 0.9988 & 0.9994 \\
\hline Space & 0.9995 & 91 & 0.0005 & 0 & $0 \%$ & 0.9992 & 0.9990 \\
\hline
\end{tabular}

Table I. Results of the proposed neural fuzzy networks for interpreting graffiti after

training for 30 times. 


\begin{tabular}{|c|c|c|c|c|c|c|c|}
\hline $\begin{array}{c}\text { Neural fuzzy } \\
\text { network }\end{array}$ & $\begin{array}{c}\text { Best } \\
\text { fitness } \\
\text { value }\end{array}$ & $\begin{array}{l}\text { Number } \\
\text { of rules }\end{array}$ & $\begin{array}{l}\text { Training } \\
\text { error } \\
\text { (MSE) for } \\
\text { the best } \\
\text { network }\end{array}$ & $\begin{array}{c}\text { Recognition } \\
\text { error rate }(\%) \\
\text { of the best } \\
\text { network for the } \\
\text { training pattern }\end{array}$ & $\begin{array}{l}\text { Testing } \\
\text { error } \\
\text { (MSE) for } \\
\text { the best } \\
\text { network }\end{array}$ & $\begin{array}{c}\text { Recognition } \\
\text { error rate (\%) } \\
\text { of the best } \\
\text { network for } \\
\text { the training } \\
\text { pattern }\end{array}$ & $\begin{array}{c}\text { Average } \\
\text { fitness } \\
\text { value }\end{array}$ \\
\hline 0 (a) & 0.9995 & 150 & 0.0005 & 0 & $10 \%$ & 0.9974 & 0.9993 \\
\hline 0 (b) & 0.9990 & 150 & 0.0010 & 0 & $0 \%$ & 0.9976 & 0.9983 \\
\hline 1 & 0.9994 & 150 & 0.0006 & 1 & $0 \%$ & 0.9990 & 0.9990 \\
\hline 2 & 0.9994 & 150 & 0.0006 & 0 & $0 \%$ & 0.9987 & 0.9990 \\
\hline 3 & 0.9995 & 150 & 0.0005 & 0 & $26.6667 \%$ & 0.9897 & 0.9992 \\
\hline 4 & 0.9997 & 150 & 0.0003 & 0 & $3.3333 \%$ & 0.9977 & 0.9996 \\
\hline 5(a) & 0.9986 & 150 & 0.0014 & 1 & 6.6667 & 0.9962 & 0.9977 \\
\hline 5(b) & 0.9981 & 150 & 0.0019 & 0 & 33.3333 & 0.9740 & 0.9966 \\
\hline 6 & 0.9993 & 150 & 0.0007 & 0 & $10 \%$ & 0.9957 & 0.9988 \\
\hline 7 & 0.9989 & 150 & 0.0011 & 1 & $6.6667 \%$ & 0.9890 & 0.9960 \\
\hline $8(\mathrm{a})$ & 0.9996 & 150 & 0.0004 & 0 & $3.3333 \%$ & 0.9968 & 0.9993 \\
\hline $8(b)$ & 0.9995 & 150 & 0.0005 & 0 & $13.3333 \%$ & 0.9928 & 0.9993 \\
\hline 9 & 0.9991 & 150 & 0.0009 & 1 & $6.6667 \%$ & 0.9987 & 0.9987 \\
\hline Back Space & 0.9996 & 150 & 0.0004 & 0 & $3.3333 \%$ & 0.9945 & 0.9994 \\
\hline Return & 0.9989 & 150 & 0.0011 & 0 & $3.3333 \%$ & 0.9945 & 0.9981 \\
\hline Space & 0.9996 & 150 & 0.0004 & 0 & $3.3333 \%$ & 0.9958 & 0.9987 \\
\hline
\end{tabular}

Table II. Results of the traditional neural fuzzy networks for interpreting graffiti after

training for 30 times. 


\begin{tabular}{|c|c|c|c|c|c|c|}
\hline $\begin{array}{c}\text { Neural fuzzy } \\
\text { network }\end{array}$ & $\begin{array}{c}\text { Best } \\
\text { fitness } \\
\text { value }\end{array}$ & $\begin{array}{c}\text { Training } \\
\text { error (MSE) } \\
\text { for the best } \\
\text { network }\end{array}$ & $\begin{array}{c}\text { Recognition error } \\
\text { rate (\%) of the best } \\
\text { network for the } \\
\text { training pattern }\end{array}$ & $\begin{array}{c}\text { Testing error } \\
\text { (MSE) for } \\
\text { the best } \\
\text { network }\end{array}$ & $\begin{array}{c}\text { Recognition error } \\
\text { rate (\%) of the best } \\
\text { network for the } \\
\text { training pattern }\end{array}$ & $\begin{array}{c}\text { Average } \\
\text { fitness } \\
\text { value }\end{array}$ \\
\hline $0(\mathrm{a})$ & 0.9993 & 0.0007 & 1 & $10 \%$ & 0.9981 & 0.9991 \\
\hline $0(\mathrm{~b})$ & 0.9993 & 0.0007 & 0 & $0 \%$ & 0.9992 & 0.9991 \\
\hline 1 & 0.9989 & 0.0011 & 2 & $0 \%$ & 0.9989 & 0.9983 \\
\hline 2 & 0.9976 & 0.0024 & 0 & $3.3333 \%$ & 0.9962 & 0.9976 \\
\hline 3 & 0.9981 & 0.0019 & 0 & $0 \%$ & 0.9962 & 0.9977 \\
\hline 4 & 0.9989 & 0.0011 & 2 & $0 \%$ & 0.9972 & 0.9988 \\
\hline $5(\mathrm{a})$ & 0.9986 & 0.0014 & 0 & $3.3333 \%$ & 0.9970 & 0.9984 \\
\hline $5(\mathrm{~b})$ & 0.9986 & 0.0014 & 0 & $0 \%$ & 0.9973 & 0.9984 \\
\hline 6 & 0.9988 & 0.0012 & 4 & $23.3333 \%$ & 0.9948 & 0.9987 \\
\hline 7 & 0.9974 & 0.0026 & 4 & $3.3333 \%$ & 0.9976 & 0.9967 \\
\hline $8(\mathrm{a})$ & 0.9988 & 0.0012 & 1 & $0 \%$ & 0.9965 & 0.9986 \\
\hline $8(\mathrm{~b})$ & 0.9989 & 0.0011 & 0 & $0 \%$ & 0.9963 & 0.9988 \\
\hline 9 & 0.9965 & 0.0035 & 13 & $3.3333 \%$ & 0.9966 & 0.9957 \\
\hline Back Space & 0.9986 & 0.0014 & 0 & $3.3333 \%$ & 0.9965 & 0.9974 \\
\hline Return & 0.9980 & 0.0020 & 0 & $0 \%$ & 0.9970 & 0.9971 \\
\hline Space & 0.9986 & 0.0015 & 0 & $0 \%$ & 0.9985 & 0.9978 \\
\hline Table III & Results & 0 the traditis & \\
\hline
\end{tabular}

Table III. Results of the traditional neural networks (15 hidden nodes) for interpreting graffiti after training for 30 times. 


\begin{tabular}{|c|c|c|c|c|c|c|}
\hline $\begin{array}{l}\text { Neural fuzzy } \\
\text { network }\end{array}$ & $\begin{array}{c}\text { Best } \\
\text { fitness } \\
\text { value }\end{array}$ & $\begin{array}{l}\text { Training } \\
\text { error (MSE) } \\
\text { for the best } \\
\text { network } \\
\end{array}$ & $\begin{array}{l}\text { Recognition error } \\
\text { rate }(\%) \text { of the } \\
\text { best network for } \\
\text { the training pattern }\end{array}$ & $\begin{array}{l}\text { Testing } \\
\text { error (MSE) } \\
\text { for the best } \\
\text { network } \\
\end{array}$ & $\begin{array}{l}\text { Recognition error } \\
\text { rate }(\%) \text { of the } \\
\text { best network for } \\
\text { the training pattern }\end{array}$ & $\begin{array}{c}\text { Average } \\
\text { fitness } \\
\text { value }\end{array}$ \\
\hline 0 (a) & 0.9993 & 0.0007 & 1 & $6.6667 \%$ & 0.9983 & 0.9992 \\
\hline $0(\mathrm{~b})$ & 0.9993 & 0.0007 & 0 & $3.3333 \%$ & 0.9981 & 0.9992 \\
\hline 1 & 0.9989 & 0.0011 & 1 & $0 \%$ & 0.9989 & 0.9986 \\
\hline 2 & 0.9986 & 0.0014 & 0 & $0 \%$ & 0.9983 & 0.9981 \\
\hline 3 & 0.9989 & 0.0011 & 0 & $3.3333 \%$ & 0.9971 & 0.9986 \\
\hline 4 & 0.9992 & 0.0008 & 2 & $6.6667 \%$ & 0.9963 & 0.9990 \\
\hline 5(a) & 0.9991 & 0.0009 & 0 & $0 \%$ & 0.9979 & 0.9989 \\
\hline $5(\mathrm{~b})$ & 0.9992 & 0.0008 & 0 & $0 \%$ & 0.9980 & 0.9990 \\
\hline 6 & 0.9989 & 0.0011 & 2 & $20 \%$ & 0.9953 & 0.9987 \\
\hline 7 & 0.9969 & 0.0031 & 5 & $3.3333 \%$ & 0.9972 & 0.9966 \\
\hline $8(\mathrm{a})$ & 0.9987 & 0.0013 & 1 & $0 \%$ & 0.9963 & 0.9986 \\
\hline $8(\mathrm{~b})$ & 0.9989 & 0.0011 & 0 & $0 \%$ & 0.9964 & 0.9988 \\
\hline 9 & 0.9968 & 0.0032 & 13 & $6.6667 \%$ & 0.9968 & 0.9957 \\
\hline Back Space & 0.9988 & 0.0012 & 0 & $3.3333 \%$ & 0.9965 & 0.9977 \\
\hline Return & 0.9984 & 0.0016 & 0 & $0 \%$ & 0.9974 & 0.9976 \\
\hline Space & 0.9986 & 0.0014 & 0 & $0 \%$ & 0.9986 & 0.9978 \\
\hline
\end{tabular}

Table IV. Results of the traditional neural networks (21 hidden nodes) for interpreting graffiti after training for 30 times. 


\section{$\underline{\text { List of Captions }}$}

Fig. 1. eBook Reader.

Fig. 2. Proposed neural fuzzy network.

Fig. 3. Block diagram of the graffiti digit and character interpreter.

Fig. 4. Graffiti digits and characters (with the dot indicating the starting point of the graffiti).

Fig. 5. Similarity values of the 16 proposed neural fuzzy networks for the 480 (30 for each type) testing graffiti.

Fig. 6. Input of digit ' 9 ' to the Annotation window using the Graffiti Pad of the eBook.

Table I. Results of the proposed neural fuzzy networks for interpreting graffiti after training for 30 times.

Table II. Results of the traditional neural fuzzy networks for interpreting graffiti after training for 30 times.

Table III. Results of the traditional neural networks (15 hidden nodes) for interpreting graffiti after training for 30 times.

Table IV. Results of the traditional neural networks (21 hidden nodes) for interpreting graffiti after training for 30 times. 